\title{
Relationship of pulmonary impairment in simple coal workers' pneumoconiosis to type of radiographic opacity
}

\author{
ANTHONY SEATON, N. LeROY LAPP, and W. KEITH C. MORGAN \\ Department of Medicine, West Virginia University Medical Center, School of Medicine, \\ Morgantown, and Appalachian Laboratory for Occupational Respiratory Diseases, National \\ Institute for Occupational Safety and Health, U.S. Public Health Service, P.O. Box 4292, \\ Morgantown, West Virginia 26505
}

\begin{abstract}
Seaton, A., Lapp, N. L., and Morgan, W. K. C. (1972). Brit. J. industr. Med., 29, 50-55. Relationship of pulmonary impairment in simple coal workers' pneumoconiosis to type of radiographic opacity. From a group of 1461 working coal miners who participated in an epidemiological study, 223 men with simple pneumoconiosis were selected on the basis of the type of small rounded opacity noted to be present in their chest films. No differences in spirometry or lung volumes were found between those with the micronodular (q) and those with pinhead (p) opacities. Twenty-five non-smoking miners with category 2 or 3 simple coal workers' pneumoconiosis were subsequently selected for further pulmonary function testing. Studies of lung volumes and pulmonary mechanics showed no difference between those with the pinhead and micronodular types of opacity; however, transfer factor was somewhat lower in those with the former.
\end{abstract}

Three types of regular opacity may be found in the chest radiograph of subjects with simple coal workers' pneumoconiosis (CWP). The smallest opacities, those less than $1.5 \mathrm{~mm}$ diameter, are known as pinhead (p), those between 1.5 and $3 \mathrm{~mm}$ as micronodular (q), while those between 3 and 10 $\mathrm{mm}$ are known as nodular ( $\mathrm{r}$ ). It has been suggested that differences exist in terms of morbid anatomy between the three types of opacity (Gough, James, and Wentworth, 1949; Ryder, Lyons, Campbell, and Gough, 1970). This study was planned to investigate physiological differences between groups of working miners with simple coal workers' pneumoconiosis of the pinhead and micronodular types (UICC/Cincinnati classification, 1970).

\section{Subjects}

As part of a nationwide survey of the prevalence and functional effects of CWP currently being carried out by the U.S. Public Health Service, 1461 working coal miners from six mines in south-western and central Pennsylvania were studied. Of these, 649 were judged to have simple CWP. In 223 of them, agreement was independently reached by two observers on the predominant type of small regular opacity present in their chest radiograph, viz., pinhead (p), micronodular (q), or nodular (r) (UICC Cincinnati classification). Subjects in whom agreement could not be reached concerning the type of opacity were excluded, as were subjects who also had small irregular opacities present. These 223 miners form the first part of this report, 52 having the pinhead, 162 the micronodular, and 9 the nodular type of opacity. Fifteen miners from the above group and a further 10 from another mine in northern West Virgina were selected for further study on the basis of the following criteria:

(1) he had been a non-smoker for at least 10 years;

(2) he had category 2 or 3 simple CWP, the predominant opacity being either $\mathbf{p}$ or $\mathbf{q}$;

(3) he had a forced expiratory volume (1 second) divided by forced vital capacity $\left(\frac{\mathrm{FEV}_{1}}{\mathrm{FVC}} \%\right)$ of $70 \%$ or greater;

(4) he had no cardiorespiratory illness other than symptoms of bronchitis. 
All participants were volunteers and agreed to undergo the tests after full explanation of the procedures. Fifteen had $\mathrm{q}$ and 10 had $\mathrm{p}$ type opacities. All save two had category 2 simple CWP, the remainder being category $3 \mathrm{q}$.

\section{Methods and materials $\mathbf{1}^{\mathbf{1}}$}

All subjects completed a modified version of the Medical Research Council short questionnaire on chronic bronchitis (1965). The subjects in the initial field study performed spirometry on an Electro Med 780 waterless spirometer. The flow-volume loops were photographed and measured to obtain forced vital capacity (FVC), forced expiratory volume in one second $\left(\mathrm{FEV}_{1}\right)$ and forced expiratory flow at $50 \%$ of FVC $\left(\mathrm{FEF}_{50}\right)($ Hankinson and Lapp, 1970). Total lung capacity (TLC) was measured by Barnhard's radiographic method as described previously (O'Shea et al., 1970). Residual volume (RV) was obtained by subtracting FVC from TLC. Normal values for the spirometry were those of Kory, Callahan, and Boren (1961) and for lung volumes the short equation of Needham, Rogan, and McDonald (1954) was used.

The 25 subjects selected for further study were investigated in the laboratory. Total lung capacity and airways resistance were measured in a constant volume body plethysmograph (DuBois, Botelho, and Comroe, 1956). Predicted normal values used were again those of Needham et al. (1954) for lung volumes and of Briscoe and DuBois (1958) for airways resistance. Transfer factor for carbon monoxide $\left(D_{L}\right)$ was measured by the single breath technique (Ogilvie, Forster, Blakemore, and Morton, 1957) modified by using the residual volume obtained in the plethysmograph and analysing the gases in a Beckman gas chromatograph. Values obtained on 20 normal male subjects in our own laboratory were used to predict the normal transfer factor on the basis of the subject's height $\left(D_{L}=1.48\right.$ ht (inches)-64).

Studies of pulmonary mechanics were made using a $10-\mathrm{cm}$ latex oesophageal balloon connected via a polythene tube to a sensitive strain gauge transducer (Milic-Emili, Mead, and Turner, 1964). Lateral oral pressure recorded at the mouthpiece was subtracted electronically from oesophageal pressure, recorded by the balloon in the lower third of the oesophagus, to obtain transpulmonary pressure. Flow measured by a pneumotachograph was integrated electronically to obtain volume. Dynamic compliance was obtained by measuring related changes in pressure and volume over eight or more respiratory cycles at three different rates of respiration. Static compliance and pulmonary recoil pressure were measured from the expiratory limb of a static pressure-volume curve.

\section{Results}

\section{Field survey}

As there were only nine subjects with $r$ opacities, they have been excluded from consideration except in one instance to be mentioned later. A comparison between the groups with $\mathrm{p}$ and $\mathrm{q}$ opacities, regardless of profusion, showed no significant difference in

${ }^{1}$ Mention of commercial concerns or products does not constitute endorsement by the U.S. Public Health Service. either spirometry or lung volumes. Table 1 records the means of the observed values expressed as a percentage of predicted values for the two groups.

The groups were divided into smokers and nonsmokers or ex-smokers and again no significant differences were found (Table 2).

When only those subjects with either category 2 or 3 simple CWP were considered, minor differences were found in the residual volume; those with $p$ and $q$ lesions, though not different from one another, were both markedly lower than those with $r$ lesions (Table 3).

As there are no satisfactory formulae for predicting $\mathrm{FEF}_{50}$, the means of the actual values for the two groups were compared and no difference was found (Table 4).

\section{Detailed study}

The mean results in the 25 selected subjects are recorded in Table 5. No significant difference was found between the two groups in age, height, years

\section{TABLE 1}

Mean Values for SPIROMEtry and Lung Volumes

\begin{tabular}{|c|c|c|c|c|}
\hline \multirow[t]{2}{*}{$\begin{array}{c}\text { Percent } \\
\text { predicted }\end{array}$} & \multicolumn{2}{|c|}{$\begin{array}{c}\text { Pinhead }(p) \\
\text { opacities }\left(52^{1}\right)\end{array}$} & \multicolumn{2}{|c|}{$\begin{array}{c}\text { Micronodular }(q \\
\text { opacities }\left(162^{1}\right)\end{array}$} \\
\hline & Mean & S.D. & Mean & S.D. \\
\hline $\begin{array}{ll}\text { FVC } & \ldots \\
\text { FEV }_{1} & \ldots \\
\text { RV } & \ldots \\
\text { TLC } & \ldots\end{array}$ & $\begin{array}{r}102 \\
94 \\
127 \\
110\end{array}$ & $\begin{array}{l}14 \\
14 \\
33 \\
14\end{array}$ & $\begin{array}{r}100 \\
94 \\
124 \\
107\end{array}$ & $\begin{array}{l}15 \\
16 \\
34 \\
15\end{array}$ \\
\hline$\frac{\text { FEV }_{1}}{\mathrm{FVC}} \%$ & 100 & 10 & 102 & 12 \\
\hline
\end{tabular}

${ }^{1}$ Number of subjects.

TABLE 2

Mean Values for SPIROMETRy and Lung Volumes RELATED TO SMOKING HABITS

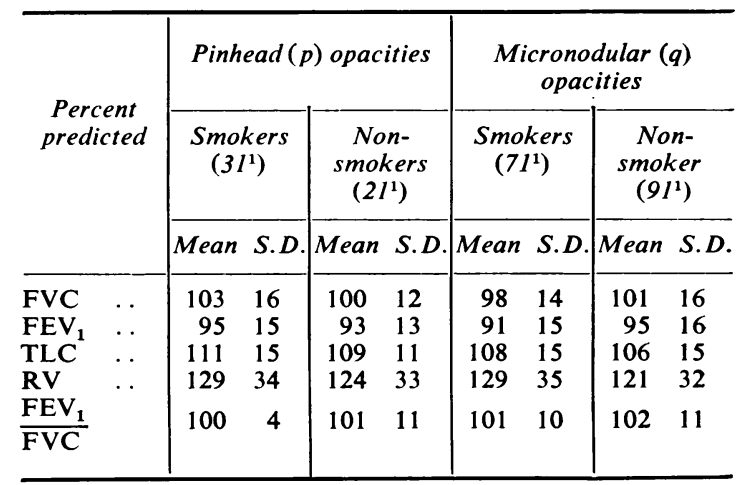

${ }^{1}$ Number of subjects 
TABLE 3

Mean Values for Spirometry and Lung Volumes in Subjects with Category 2 or 3 Simple CWP

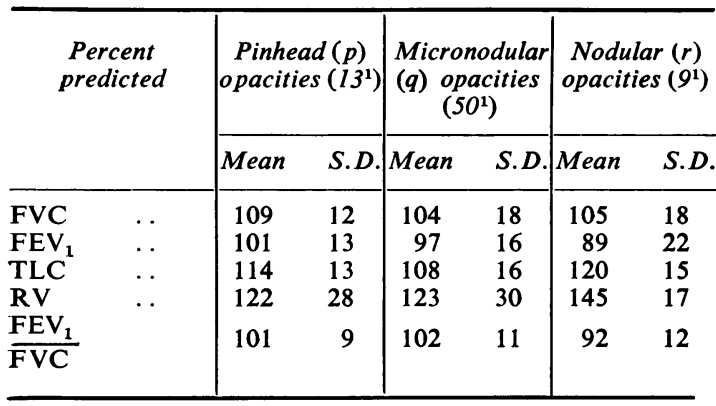

${ }^{1}$ Number of subjects

spent underground or pack-years of cigarettes smoked. Six of the subjects with type $p$ opacities and four of those with q opacities gave a history of cough and sputum satisfying the criteria of the Medical Research Council for chronic bronchitis. In spite of this, mean airways resistance was significantly higher at the $5 \%$ level in the group with $\mathrm{q}$ lesions; however, this difference disappeared when resistance was expressed in terms of specific airway conductance. The only other significant differences between the two groups lay in the transfer factor $\left(D_{\mathrm{L}}\right)$ either expressed as $\mathrm{ml} / \mathrm{min} / \mathrm{mmHg}$, as a percentage of predicted or divided by total lung capacity (TLC) as shown in the Figure. The differences were tested by a $t$ test for unpaired samples (Table 6).

Dynamic compliance was shown to be frequencydependent in 17 of the subjects, 6 with p opacities and 11 with q. Seven of these had clinical chronic bronchitis, leaving 10 in whom the pneumoconiosis may be assumed to have been responsible. The detailed results of the changes in mechanics have been reported elsewhere as part of a comprehensive study of lung mechanics in coal workers (Seaton, Lapp, and Morgan, 1971).

TABLE 4

Mean Forced Expiratory Flow Rates at 50\% OF FVC

\begin{tabular}{|c|c|c|c|c|c|c|}
\hline & \multicolumn{3}{|c|}{ Pinhead ( $p$ ) opacities } & \multicolumn{3}{|c|}{$\begin{array}{l}\text { Micronodular }(q) \\
\text { opacities }\end{array}$} \\
\hline & Total & $\begin{array}{l}\text { Non- } \\
\text { smoker }\end{array}$ & Smoker & Total & $\begin{array}{l}\text { Non- } \\
\text { smoker }\end{array}$ & Smoker \\
\hline $\begin{array}{l}\text { No. of } \\
\text { subjects }\end{array}$ & 52 & 21 & 31 & 162 & 91 & 71 \\
\hline $\begin{array}{l}\text { Mean FEF } \\
\text { (1/s) } \\
\text { S.D. }\end{array}$ & $\begin{array}{l}4 \cdot 08 \\
1 \cdot 49\end{array}$ & $\begin{array}{l}4 \cdot 00 \\
1 \cdot 70\end{array}$ & $\begin{array}{l}4 \cdot 14 \\
1 \cdot 36\end{array}$ & $\begin{array}{l}4 \cdot 30 \\
1.55\end{array}$ & $\begin{array}{l}4.41 \\
1.59\end{array}$ & $\begin{array}{l}4 \cdot 15 \\
1 \cdot 50\end{array}$ \\
\hline
\end{tabular}

TABLE 5

Mean Data on 25 Working Miners

\begin{tabular}{|c|c|c|c|c|}
\hline & \multicolumn{2}{|c|}{$\begin{array}{l}\text { Micronodular } \\
\text { opacity }\left(15^{1}\right)\end{array}$} & \multicolumn{2}{|c|}{$\begin{array}{c}\text { Pinhead } \\
\text { opacity }\left(10^{1}\right)\end{array}$} \\
\hline & Mean & S.D. & Mean & S.D. \\
\hline Age (yr) & 55 & 5 & 54 & 6 \\
\hline Height (inches) & 70 & 3 & 68 & 2 \\
\hline Years underground .. & 35 & 8 & 31 & 11 \\
\hline Pack years smoked ... & 4 & 8 & 8 & 10 \\
\hline $\begin{array}{l}\mathrm{FEV}_{1} / \mathrm{FVC} \% \\
\text { Total lung capacity }\end{array}$ & 75 & 5 & 76 & 8 \\
\hline $\begin{array}{c}\text { (litres) } \\
\text { Total lung capacity }\end{array}$ & $6 \cdot 66$ & 0.83 & $6 \cdot 62$ & $1 \cdot 13$ \\
\hline $\begin{array}{l}\text { Total lung capacity } \\
\text { ( } \% \text { predicted) } \\
\text { Residual volume(litres) }\end{array}$ & $\begin{array}{c}94 \\
1 \cdot 97\end{array}$ & $\begin{array}{c}12 \\
0 \cdot 46\end{array}$ & $\begin{array}{c}94 \\
2 \cdot 00\end{array}$ & $\begin{array}{c}11 \\
0.86\end{array}$ \\
\hline $\begin{array}{l}\text { Residual volume } \\
\text { (\% predicted) }\end{array}$ & 28 & . & -0 & 0 \\
\hline RV/TLC \% ... & 30 & $\begin{array}{r}10 \\
6\end{array}$ & 30 & $\begin{array}{r}31 \\
8\end{array}$ \\
\hline $\begin{array}{l}\text { Airways resistance at } \\
\text { functional residual } \\
\text { capacity }\left(\mathrm{cm} \mathrm{H}_{2} \mathrm{O} / 1 / \mathrm{s}\right.\end{array}$ & $1 \cdot 90$ & 0.58 & $1 \cdot 43$ & $0 \cdot 48^{2}$ \\
\hline $\begin{array}{l}\text { Airways resistance } \\
(\% \text { predicted })\end{array}$ & 130 & 44 & 93 & $31^{2}$ \\
\hline $\begin{array}{l}\text { Specific conductance } \\
\left(1 / \mathrm{s} / \mathrm{cm} \mathrm{H} \mathrm{H}_{2} \mathrm{O} / \mathrm{l}\right)\end{array}$ & $0 \cdot 23$ & 0.03 & $0 \cdot 24$ & 0.06 \\
\hline $\begin{array}{l}\text { Static compliance } \\
\left(1 / \mathrm{cm} \mathrm{H}_{2} \mathrm{O}\right) \ldots \\
\text { Static compliance }\end{array}$ & 0.23 & 0.06 & $0 \cdot 25$ & 0.06 \\
\hline $\begin{array}{l}\text { (\% predicted) } \\
\text { Pulmonary recoil pres- }\end{array}$ & 85 & 18 & 101 & 23 \\
\hline sure at TLC $\left(P_{e l}\right)$ & 27 & 6 & 27 & 6 \\
\hline $\begin{array}{l}\text { Pel/TLC } \\
\text { Transfer factor }\end{array}$ & $4 \cdot 1$ & $1 \cdot 1$ & $4 \cdot 1$ & $1 \cdot 0$ \\
\hline$(\mathrm{ml} / \mathrm{min} / \mathrm{mmHg})$ & $41 \cdot 0$ & $5 \cdot 8$ & $35 \cdot 5$ & $6 \cdot 0^{2}$ \\
\hline $\begin{array}{l}\text { Transfer factor }\left(D_{\mathcal{L}}\right) \\
(\% \text { predicted })\end{array}$ & $105 \cdot 7$ & $12 \cdot 4$ & $95 \cdot 0$ & $12 \cdot 5^{2}$ \\
\hline $\begin{array}{lll}D_{\mathrm{L}} / \mathrm{TLC} & \ldots & \ldots\end{array}$ & $6 \cdot 2$ & 0.8 & $5 \cdot 4$ & $0.7^{2}$ \\
\hline $\begin{array}{l}\text { Dynamic compliance at } \\
60 \text { breaths/minute }\end{array}$ & & & & \\
\hline $\begin{array}{c}\text { Tidal dynamic } \\
\text { compliance }\end{array}$ & 72 & 24 & 71 & 12 \\
\hline
\end{tabular}

${ }^{1}$ Number of subjects

'Significant difference

TABLE 6

Test for Differences between Groups WITH $p$ AND q LESIONS

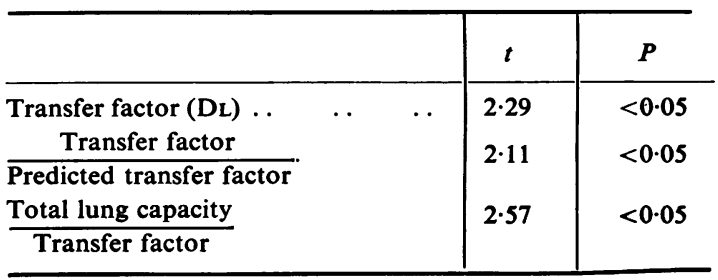

\section{Discussion}

Interest in physiopathological differences between the different radiographic types of opacity found in 


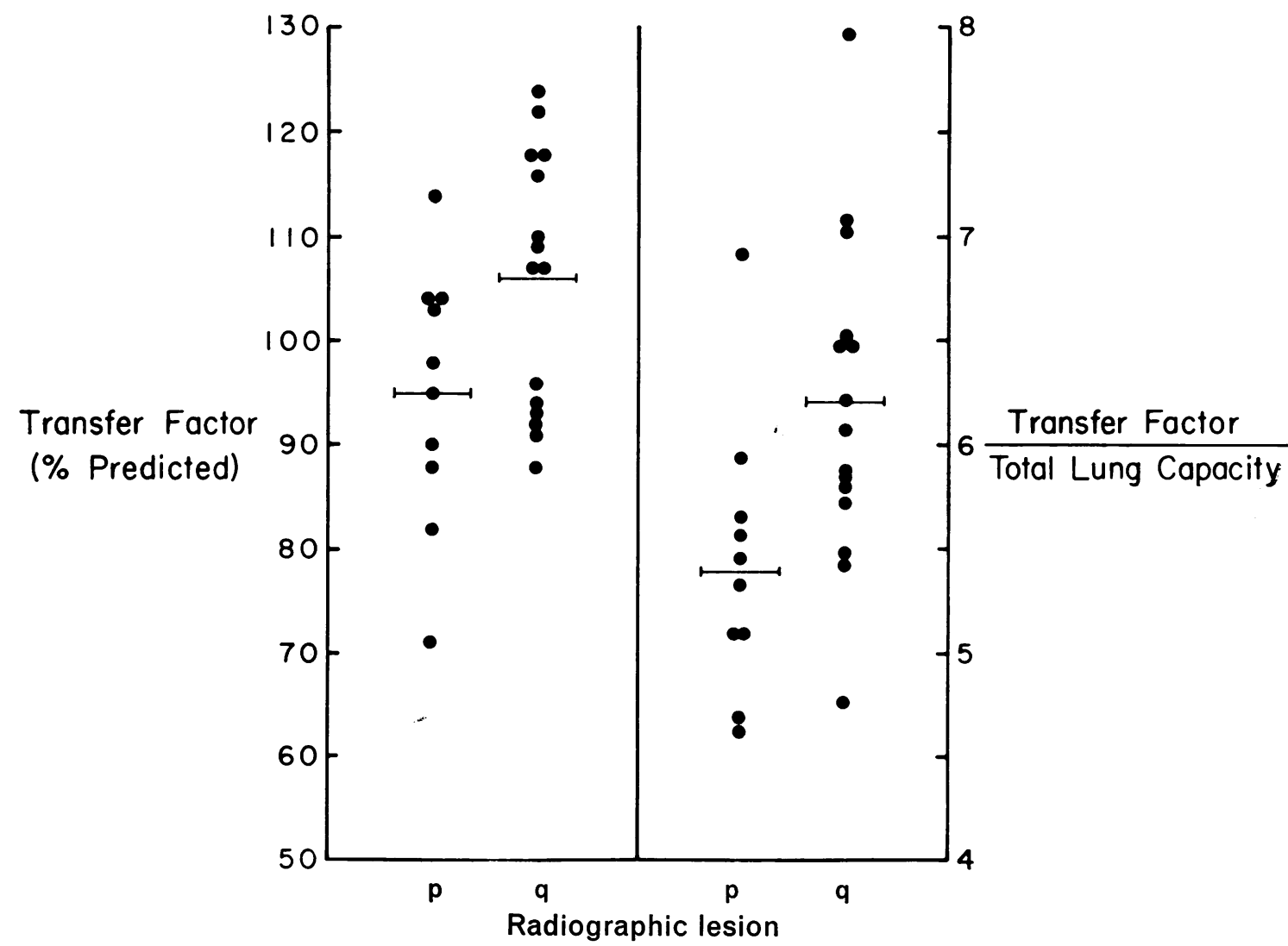

FIGURE Values for transfer factor and transfer factor/total lung capacity in miners with $\mathrm{p}$ and $\mathrm{q}$ opacities.

simple pneumoconiosis was initially aroused by finding that subjects with nodular lesions (r) had an increased frequency of positive serological tests for rheumatoid arthritis (Caplan, Payne, and Withey, 1962). Gough et al. (1949) had previously suggested that subjects with the $p$ type of opacity had more focal emphysema, and more recently some support for this has come from the pathological work of Ryder et al. (1970). Sartorelli, Baraldi, Grieco, and Zedda (1963) investigated steady state $D_{L}$ in 31 miners, and their results indicate lower values in those with $\mathrm{p}$ than those with $\mathrm{q}$ lesions, though these authors did not comment on this. Englert and De Coster (1965) studied single breath $D_{L}$ in 41 miners and found those with the $\mathrm{p}$ type of opacity had lower values than those with $q$ opacities. When $D_{L}$ was divided by total lung capacity, those with p opacities had abnormally low values compared to the authors' normal controls.

Lyons, Clarke, Hall, and Cotes (1967), using the single breath technique, found lower values for $D_{\mathbf{L}}$ in those of their subjects with $p$ than in those with $q$ opacities, but when corrected for differences in cigarette smoking between the two groups, this finding lost its statistical significance. These authors also found that the group with a lower $D_{L}$ had a significant reduction in pulmonary capillary blood volume and in diffusing capacity of the membrane. Recently, Cotes, Deivanayagam, and Field (1970) have reported the results of more detailed investigations into the physiology of subjects with $p$ and $q$ types of opacity found in simple CWP. They found a lower $D_{L}$ and $D_{L}$ divided by TLC in the group with $\mathrm{p}$ lesions and also noted that this group had a slight increase in lung compliance. They suggested that these changes were related to the more frequent occurrence of focal emphysema in this type of lesion.

The present study is the first in which a comparison between the physiological effects of different types of radiographic opacities has been made on a large sample of working miners. We have found no significant difference in spirometry between miners with the $\mathrm{p}$ and $\mathrm{q}$ opacities. Our mean spirometry values for both groups were close to $100 \%$ of predicted, and in regard to lung volumes, a similar increase in residual volume was noted in both groups. This finding has been confirmed in a larger 
sample (Morgan et al., 1971). It was necessary to subject selected men to more detailed scrutiny in the laboratory before any difference could be found, and the results of this study confirm the previous findings of a lower $D_{L}$ in subjects with the $p$ type of opacity. It should be noted, however, that in no case in this series, and only very infrequently in the literature (Lapp and Seaton, 1971), has simple CWP been associated with an abnormally low $D_{L}$. In the uncomplicated disease $D_{L}$ probably never declines to the levels seen in interstitial fibrosis and is thus unlikely to be associated with symptoms.

The cause of the difference in $D_{L}$ between the two groups is not clear. If it were related to more focal emphysema, then other indices of emphysema, viz., TLC, RV, RV divided by TLC, pulmonary recoil pressure, and coefficient of retraction (Schlueter, Immekus, and Stead, 1967), should show a similar difference between the two groups. However, it is possible that the lower $D_{L}$ reflects a loss of surface area for diffusion, but that the changes in lung volume and mechanics are masked by the presence of slightly more interstitial fibrosis in those with $p$ opacities.

Another possible explanation for the difference is that there is greater inequality between ventilation and perfusion in the group with the $p$ type of opacity. The present results show no difference between the two groups in frequency dependence of compliance, a finding which suggests that small airways obstruction, while present in both groups, does not predominate in either. Gross abnormalities of perfusion have not been demonstrated in simple CWP (Seaton, Lapp, and Chang, 1971) but minor arteriolar narrowing may exist (Naeye and Laqueur, 1970) and regional ventilation-perfusion inequalities are yet to be investigated in these subjects. Lavenne, Meersseman, and Brasseur (1965) have argued strongly that ventilation-perfusion inequalities rather than interstitial fibrosis account for the gas exchange and diffusion abnormalities found in coal workers.

The findings in this study indicate that in simple CWP no differences in pulmonary function exist between subjects with the $p$ and $q$ types of opacity except in regard to the transfer factor $\left(D_{L}\right)$. Frequency dependence of compliance and minor mechanical abnormalities were shown to occur with equal frequency with both types of opacity.

We wish to thank Dr. Eugene P. Pendergrass for his interpretation of the films, Mr. Robert B. Reger and Mr. Ira Buckalew for statistical help, and Mr. Bruce Shipe for technical assistance.

\section{References}

Briscoe, W. A., and DuBois, A. B. (1958). The relationship between airway resistance, airway conductance and lung volume in subjects of different age and body size.J. clin. Invest., 37, 1279-1285.
Caplan, A., Payne, R. B., and Withey, J. L. (1962). A broader concept of Caplan's syndrome related to rheumatoid factors. Thorax, 17, 205-212.

Cotes, J. E., Deivanayagam, C. M., and Field, G. B. (1970) Relation between types of simple pneumoconiosis ( $p, m$ and $n$ ) and lung function. Third International Conference on Inhaled Particles, London, September 1970.

DuBois, A. B., Botelho, S. Y., and Comroe, J. H. (1956). A new method for measuring airway resistance in man using a body plethysmograph: values in normal subjects and in patients with respiratory disease. J. clin. Invest., 35, 327-335.

Englert, M., and De Coster, A. (1965). La capacité de diffusion pulmonaire dans l'anthracosilicose micronodulaire. J. franç. Méd. Chir. thor., 19, 159-173.

Gough, J., James, W. R. L., and Wentworth, J. E. (1949). Comparison of radiological and pathological changes in coal workers' pneumoconiosis. J. Fac. Radiol. (Lond.), 1 28-39.

Hankinson, J. L., and Lapp, N. L. (1970). Time-pulse generator for flow-volume curves. J. appl. Phys., 29, 109-110.

Kory, R. C., Callahan, R., and Boren, H. G. (1961). Clinica spirometry in normal men. Amer. J. Med., 30, 243-258.

Lapp, N. L., and Seaton, A. (1971). Pulmonary function in coal workers' pneumoconiosis. In Coal Workers' Pneumoconiosis (monograph) edited by Key, Kerr, and Bundy. Academic Press, New York (In press).

Lavenne, F., Meersseman, F., and Brasseur, L. (1965) Fibrose interstitielle diffuse et pneumoconiose des houilleurs. Rev. Inst. Hyg. Mines, 20, 33-42.

Lyons, J. P., Clarke, W. G., Hall, A. M., and Cotes, J. E. (1967). Transfer factor (diffusing capacity) for the lung in simple pneumoconiosis of coal workers. Brit. med. J., 4, 772-774.

Medical Research Council Committee Report on the Aetiology of Chronic Bronchitis (1965). Definition and classification of chronic bronchitis for clinical and epidemiological purposes. Lancet, 1, 775-779.

Milic-Emili, J., Mead, J. and Turner, J. M. (1964). Topography of esophageal pressure as a function of posture in man.J. appl. Physiol., 19, 212-216.

Morgan, W. K. C., Burgess, D. B., Lapp, N. L., Seaton, A., and Reger, R. B. (1971). Hyperinflation of the lungs in coal miners. Thorax, 26, 585-590.

Naeye, R. L., and Laqueur, W. A. (1970). Chronic cor pulmonale: Its pathogenesis in Appalachian bituminous coal workers. Arch. Path., 90, 487-493.

Needham, C. D., Rogan, M. C., and McDonald, I. (1954). Normal standards for lung volumes, intrapulmonary gas-mixing and maximum breathing caparity. Thorax, 9 , 313-325.

Ogilvie, C. M., Forster, R. E., Blakemore, W. S., and Morton, J. W. (1957). A standardized breath-holding technique for the clinical measurement of the diffusing capacity of the lung for carbon monoxide. J. clin. Invest . 36, 1-17.

O'Shea, J., Lapp, N. L., Russakoff, A. D., Reger, R., and Morgan, W. K. C. (1970). Determination of lung volumes from chest films. Thorax, 25, 544-549.

Ryder, R., Lyons. J. P., Campbell, H., and Gough, J. (1970). Emphysema in coal workers' pneumoconiosis. Brit. med.J., 3, 481-487.

Sartorelli, E., Baraldi, V., Grieco, A., and Zedda, S. (1963). La capacita di diffusione polmonare dei gas nei silicotici. Med. d. Lavoro, 54, 191-200.

Schlueter, D. P., Immekus, J., and Stead, W. W. (1967) Relationship between maximal inspiratory pressure and total lung capacity (coefficient of retraction) in normal subjects and in patients with emphysema, asthma, and diffuse pulmonary infiltration. Amer. Rev. resp. Dis., 96, 656-665. 
Seaton, A., Lapp, N. L., and Chang, C. H. J. (1971). Lung perfusion scanning in coal workers' pneumoconiosis. Amer. Rev. resp. Dis., 103, 338-349.

,-- and Morgan, W. K. C. (1971). Lung mechanics and frequency dependence of compliance in coal miners. Submitted for publication.
UICC/Cincinnati classification of the radiographic appearances of pneumoconioses. A cooperative study by the UICC Committee (1970). Chest, 58, 57-67.

Received for publication April 13, 1971 